\title{
Hydrous Non-Crystalline Phosphates: Structure, Function and a new White Pigment
}

\author{
Renato Rosseto, Ádamo C. M. A. dos Santos and Fernando Galembeck* \\ Instituto de Química, Universidade Estadual de Campinas, CP 6154, 13084-862, Campinas - SP, Brazil
}

\begin{abstract}
Sólidos inorgânicos não-cristalinos hidratados são em grande parte negligenciados devido a pouca compreensão de suas complexas propriedades físico-químicas e estruturais. Apesar disso, eles apresentam uma química muito rica e vasta, de interesse tanto do ponto de vista científico como tecnológico. Este trabalho resenha as características gerais dos sólidos nãocristalinos hidratados, com ênfase especial nos (poli)fosfatos de alumínio. Variações nos precursores e concentração, temperatura, envelhecimento e $\mathrm{pH}$ da reação de formação podem propiciar a formação de uma miríade de funções e compostos diferenciados. Produtos adequados a diferentes aplicações, todos eles fosfatos de alumínio amorfos, exemplificam o enorme potencial dos sólidos não-cristalinos.
\end{abstract}

\begin{abstract}
Hydrated non-crystalline inorganic solids are often neglected due to the limited comprehension of their complex physico-chemical and structural properties. However, these non-crystalline materials exhibit a rich and varied chemistry, interesting for scientific and technological reasons. This work reviews general aspects of formation of hydrated non-crystalline solids, with special emphasis on aluminum (poly)phosphate materials. Precursors and concentration variations, temperature, ageing and reaction $\mathrm{pH}$ are trivial synthetic variables, but they promote the formation of a myriad of compounds adequate for many functions. Amorphous aluminum phosphates are widely employed in different industrial applications, providing good examples of the potential of hydrous amorphous solids.
\end{abstract}

Keywords: non-crystalline solids, ionic solids, aluminum phosphate, amorphous polyphosphate

\section{Introduction}

\subsection{Neglected Chemistry}

Structure-property relationships are well established in crystalline inorganic solids, but similar progress has yet to be achieved in the case of amorphous materials. Determination of the atomic-scale structure of amorphous solids is generally acknowledged as a great scientific and technological challenge, and several analytical ${ }^{1}$ (X-ray, light or neutron scattering, nuclear magnetic resonance, Raman, infrared, Mössbauer spectroscopy, high performance liquid chromatography, mass spectrometry and others) and modeling techniques ${ }^{2}$ (crystal-based models, Monte Carlo and molecular dynamics simulation and others) are employed to elucidate their structural features.

There is currently much information on the structure of glasses ${ }^{1}$ but much less on particulate amorphous solids.

*e-mail: fernagal@iqm.unicamp.br
The most frequently employed techniques for the study of the structural features of amorphous materials are $\mathrm{X}$-ray and neutron scattering. ${ }^{3}$ AFM imaging with atomic resolution was recently achieved. ${ }^{3}$ Although these methods can be applied to virtually any solid, the resulting information cannot often be interpreted unambiguously. In crystalline solids, the structure is specified in terms of a unit cell and translational symmetry; on the other hand, the structure of an amorphous solid is characterized by a lack of symmetry and periodicity, and the fact that they are normally isotropic on a macroscopic scale means that the information obtained from a diffraction experiment is a one-dimensional correlation function, from which regeneration of the underlying three-dimensional structure can never be unique. ${ }^{4}$

Due to the problems associated to structural characterization coupled to the apparent triviality and lowreproducibility met in the preparation of many noncrystalline inorganic solids, such as hydroxides, hydrated phosphates, silicates and oxides, in many cases, the 
potential of these compounds as objects of scientific investigation is often neglected.

Although they lack structural order, non-crystalline materials prepared carefully have reproducible properties, but some of these features vary widely, depending on the synthetic procedure and details of the resulting structure.

Precipitate formation is driven towards a chemical dynamic equilibrium state involving the precipitate and solute ions. If the ionic product of the salt exceeds its solubility product constant $\left(\mathrm{K}_{\mathrm{sp}}\right)$, precipitation will occur. However this simple description is hardly applicable to the formation of hydrous silicates, phosphates and hydroxides from multivalent ions, because the "precipitates" exhibit different forms and stoichiometries during the formation and ageing. ${ }^{5}$

For instance, the formation of aluminum phosphates by neutralization of an acidic solution of $\mathrm{Al}^{3+}$ and hydrogenphosphate ions can be affected by a number of factors, among which: precursor ions variability and concentration, stoichiometry, temperature during reaction process and especially the precipitation $\mathrm{pH}$. Charging the product formation pathway, a myriad of new compounds exhibiting particular characteristics is obtained. Some features of the precipitates are:

(i) They are complex, appearing as amorphous hydrated structures or complex coprecipitated mixtures, with different phosphate and aluminum species formed by multiple equilibria reactions and distributed according to hitherto unknown patterns, perhaps random. For example, in aqueous solutions with a $\mathrm{pH}$ lower than 3 , aluminum exists as the aquo-complex ion $\left[\mathrm{Al}\left(\mathrm{H}_{2} \mathrm{O}\right)_{6}\right]^{3+}$, usually abbreviated as $\mathrm{Al}^{3+}$. In a less acidic solution, $\left[\mathrm{Al}\left(\mathrm{H}_{2} \mathrm{O}\right)_{6}\right]^{3+}$ undergoes successive deprotonation, forming $\left[\mathrm{Al}\left(\mathrm{H}_{2} \mathrm{O}\right)\right]_{5}(\mathrm{OH})^{2+}$ and a myriad of successive hydrocomplex salts. Minimum solubility occurs at $\mathrm{pH}$ around 7 with the precipitation of hydrous $\mathrm{Al}(\mathrm{OH})_{3}$. Finally, in a more basic solution this solid redissolves, due to the formation of tetrahedral aluminate ion $\left[\mathrm{Al}(\mathrm{OH})_{4}\right]^{-6}{ }^{-}$Besides, aluminum(III) can be detected as $\mathrm{Al}_{2} \mathrm{O}_{10}$ dimers in acid condition. ${ }^{7}$ Ion protonation/ deprotonation also leads to the formation of multiple phosphate species. In the case of aluminum polyphosphate, this leads to a large number of complex species. ${ }^{8}$

(ii) The precipitates have net charges and variable stoichiometry. The ratios of phosphate groups to hydroxyl or aluminum atoms can vary widely. ${ }^{1,9}$

(iii) Ions within the precipitate exhibit different solvation degrees around the cores, including condensed oxo bridges that promote the formation of polynuclear complexes in monomeric or polymeric blocks. ${ }^{10}$ Phosphate ion condensation/polymerization leads to the formation of condensed phosphates, that can be linear, cyclic and/ or cross-linked/branched phosphates, ${ }^{11}$ formed upon drying at higher temperatures. In many aspects, inorganic phosphate solids are recognized as polymers composed of chain-like structures like organic polymers. ${ }^{12}$ Amorphous inorganic phosphate solids are stabilized by electrostatic and hydration bonds, with a strong participation of hydroxi and hydrogen bridges. Even though the ionic bonds in inorganic phosphate solids are energetically strong, they are also labile as usual for electrostatic bonds, and their dissociation and reassociation involve low activation energies.

Given these characteristics, amorphous phosphate solids can be classified as intermediate structures between non-linear polymers, ionic liquids and glasses.

This review provides a general overview of the singularities of non-crystalline inorganic solids, with an emphasis on aluminum phosphates. Many different compounds together with their properties and applications are described. Publication pattern on other particulate amorphous materials is also examined, evidencing the dominance of phosphates and silica. Thermodynamic and kinetic aspects of particle formation and stability are discussed together with current needs for further research and for establishing an adequate conceptual framework.

\section{Amorphous Phosphate Structure: Singularities and Functions}

Although neglected, the chemistry of amorphous solids such as aluminum phosphates has not been forsaken. In recent years, an increasing number of researchers have explored these compounds structural peculiarities to develop a wide range of innovative technologies. Such applications are strongly dependent on the method of synthesis of these amorphous compounds. Variables such as addition method of raw materials, $\mathrm{P} / \mathrm{Al}$ ratios and calcination temperature are decisive for the final product characteristics.

\subsection{Catalysts}

Many papers have been published on the preparation of aluminum phosphate as a catalyst support including sol-gel synthesis techniques with raw materials that include commonly available salts of aluminum and a variety of phosphate sources. ${ }^{13-17}$

In the conventional method, established by Hill et al..$^{13}$ and Kehl, ${ }^{14}$ aluminum phosphates precipitate by neutralization in a batch stirred reactor of a solution containing aluminum and phosphate ions. The aluminum phosphate remains in the reactor as fresh reactants are added. This method is used for synthesizing amorphous 
Al-rich $\mathrm{AlPO}_{4}$ and yields homogeneous amorphous aluminum phosphate (with Al/P ratio between 5:1 to 1:1) with a surface area of 100 to $300 \mathrm{~m}^{2} / \mathrm{g}$ with pore-diameter less than $1 \mu \mathrm{m}$ and pore volume higher than $0.1 \mathrm{~cm}^{3} / \mathrm{g}$. This is combined with 0.1 to $4 \%$ of chromium, yielding a catalyst for ethylene polymerization. ${ }^{14}$

The superior textural and acid-base properties of amorphous $\mathrm{AlPO}_{4}$ obtained by the sol-gel method have been reported. ${ }^{18-20}$ Amorphous Al-rich $\mathrm{AlPO}_{4}$ is more thermally stable than Al-poor compositions that crystallize at much lower temperatures. Aluminum ions, in these mixed phosphates, play an important role in avoiding the sintering of solids, which is mainly responsible for lowering surface areas. Also the increasing amount of aluminum ions in the amorphous solid leads to a higher number of acid-base sites what improve the system catalytic performance. ${ }^{21}$

\subsection{Vaccine adjuvants}

Aluminum phosphates are also being extensively used as adjuvants in a wide range of vaccines, ${ }^{22}$ where they stimulate the response of the immunity system. Besides aluminum phosphates, only aluminum hydroxides and potassium aluminum sulfate are used to manufacture currently licensed vaccines in the United States. ${ }^{23}$ The mechanism of action of aluminum adjuvants is complex and not fully understood although extensive studies have been done to determine the physical-chemical characteristics of aluminum adjuvants and their effects on the adsorption of proteins..$^{24,25}$ Aluminum phosphate and alum-precipitated vaccine adjuvants have been classified as amorphous aluminum hydroxyphosphate with a little sulfate. Depending upon the conditions under which these amorphous phosphates are prepared, the P/Al ratio varies, which results in isoelectrical point $(\mathrm{pI})$ values ranging from 5 to 7 . The amorphous nature of these compounds contributes to a high surface area which favors protein adsorption. Thus, negatively charged diphtheria toxoid adsorbs onto aluminum phosphate with a pI close to 7 at $\mathrm{pH} 6.0$ but not at neutral $\mathrm{pH}$.

\subsection{Thin films}

Amorphous materials are used as thin films on metals and alloys, glass, and ceramic substrates. Sambasivan and Steiner ${ }^{26,27}$ using sol-gel techniques developed a microstructurally dense amorphous aluminum phosphate material using as precursor phosphorus pentoxide and hydrated aluminum nitrate, dissolved in ethanol or other liquids. Pyrolysis of the precursor at temperatures above
$500{ }^{\circ} \mathrm{C}$ yields a stable microstructurally dense material which is resistant to crystallization up to $1400{ }^{\circ} \mathrm{C}$. This chemically durable and thermally stable aluminum phosphate provides non-porous films that protect metallic surfaces against abrasion, corrosion and oxidation, over a range of temperatures and harsh environments. High emissivity, non-wetting and non-stick behavior of the surface make them useful in a series of applications. ${ }^{26,27}$

\subsection{Pigments}

A nano-structured amorphous aluminum phosphate with closed pores was successfully obtained by the authors, ${ }^{28,29}$ see Figure 1. The formation of this amorphous aluminum phosphate is carried out through the simultaneous mixture of three reagent solution, i.e., phosphoric acid, aluminum sulfate, and sodium hydroxide. Process details are described elsewhere. ${ }^{28,29}$

This aluminum phosphate is a hydrous, non-crystalline and neutral solid made out of nanoparticles and it is completely different from existing aluminum phosphates or polyphosphates, in many aspects:

(i) The nanoparticles formed have a core-and-shell structure, in other words, they have shells chemically different from their cores. Thus the presence of voids, within particles dried at rather low temperatures are caused by the particles lost weight when de-swelling. Since their skins do not undergo contraction, hollow particles are formed since the plasticity of the particle cores is higher than that of the shells, see Figure 2.

(ii) It does not have a definite stoichiometry, thus it is better conceived as a cross-linked ionic polymer than as a salt;

(iii) Since stoichiometry is not definite, various grades of this aluminum phosphate can be prepared by changing the fabrication process and thus the final product composition;

(iv) It is made under very fine $\mathrm{pH}$ control and it is nearly neutral thus avoiding environmental and toxicological problems;

(v) The non-stoichiometry together with the noncrystallinity of this aluminum phosphate (both slurry and powder) and the carefully controlled water content of dry powder allow for easy swelling control that is essential for its performance;

(vi) The nano-sized particles are easily dispersed and they are stable towards settling, which is very important for making uniform paint dispersions;

(vii) The aluminum phosphate nanoparticles are strongly compatible with latex particles, by the mechanisms of capillary adhesion (in the dispersion drying 
stage) followed by ion-cluster mediated electrostatic adhesion (in the dry film). This compatibility is so high that bicontinuous networks are formed, in many cases;

(viii) It is also strongly compatible with many other particulate solids commonly used as paint fillers, such as the various silicates, carbonates and oxides found in formulated water-based dispersions. This contributes to the cohesion and strength of the paint dry film.

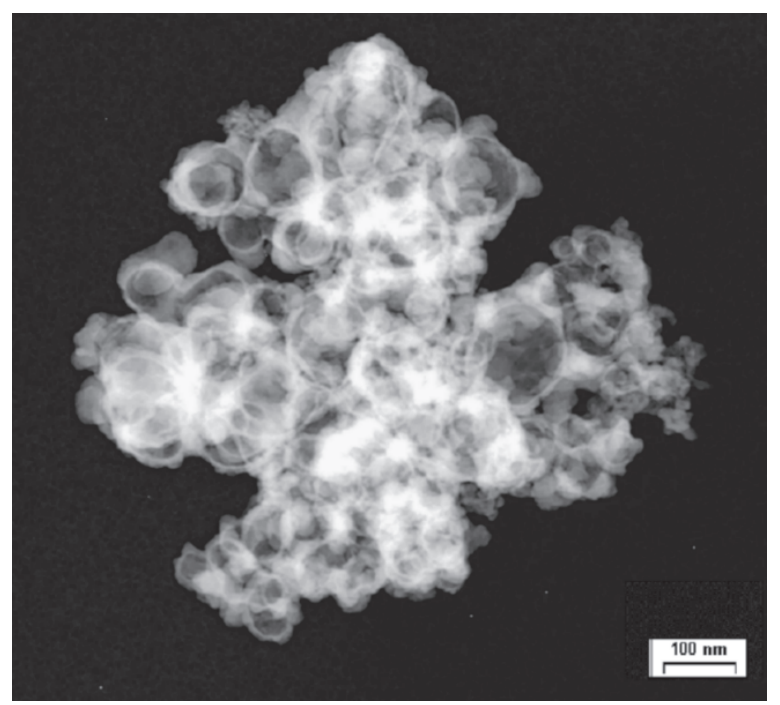

Figure 1. Bright field transmission electron micrograph of the nanostructured aluminum phosphate.

To understand how this new white pigment performs within a drying paint film, it is interesting to compare it to the current industry standard white pigment, titanium dioxide. A basic $\mathrm{TiO}_{2}$ water-based paint is made out of a suitable latex dispersion and pigment particles. The latex particles are responsible for making a coalesced film filled with the pigmented particles, which are responsible for the film hiding power. Many additives are also used: inorganic fillers, which decrease the requirements of resin and pigment; coalescing agents, which improve resin film formation; dispersants and rheological modifiers that prevent pigment and filler caking and thus they improve the paint shelf-life together with the rheological paint properties.

The pigment and filler particles are dispersed in the resin film. In this case, hiding power is largely dependent on the particle refractive indices and sizes. $\mathrm{TiO}_{2}$ is currently the standard white pigment because of its large refractive index and the absence of light absorption in the visible region.

There are many, large differences with the previous case:

(i) The film is not just a resin film: rather it is formed by enmeshed resin and aluminum phosphate. It is thus a nanocomposite film that combines two interpenetrating phases with different properties to achieve synergistic benefits, concerning film mechanical properties and resistance to water and to other aggressive agents. This is a new concept for the paint industry but it is already largely used in the development of new, high-performance materials generally described as nanohybrids or nanocomposites. ${ }^{30}$

(ii) Good film hiding power is obtained at lower $\mathrm{TiO}_{2}$ contents, because the film contains a large amount of closed pores that do also scatter light. Moreover, if $\mathrm{a} \mathrm{TiO}_{2}$ particle is adjacent to one of these voids, it will scatter
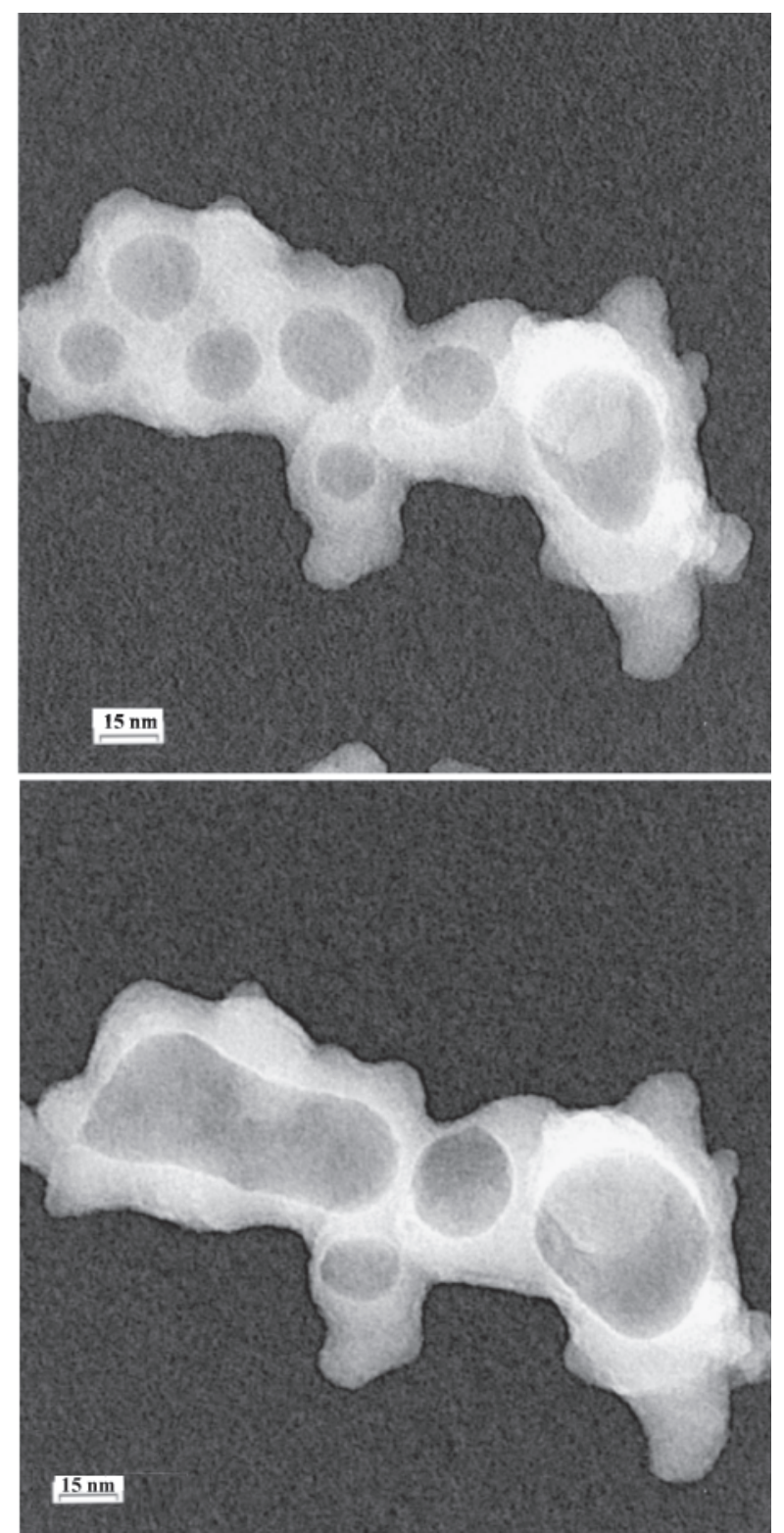

Figure 2. Successive bright field transmission electron micrographs of the nanostructured aluminum phosphate particles, under the electron beam. The plasticity of the particle core is higher than that of the shell allowing the voids to expand without changing the particle surface. 
much more than if it is fully surrounded by resin, due to the larger refractive index gradient. This creates a synergism between $\mathrm{AlPO}_{4}$ and $\mathrm{TiO}_{2}$, as far as the hiding power is concerned.

It is noteworthy that, by using lower ratios of $\mathrm{P} / \mathrm{Al}$, the amorphous aluminum phosphates obtained can be molded at relatively low temperature and used in the fabrication of solid objects. ${ }^{31}$ Similar results were also obtained when using aluminum polyphosphates. ${ }^{10}$

\subsection{Other materials}

Aluminum phosphates have been used as building blocks for a number of new materials endowed with interesting or unusual properties. They can be formed into gels having high proton conductivity ${ }^{32}$ they form hybrid films with polypyrrol ${ }^{33}$ and polyaniline ${ }^{34}$ and they host organic dyes. ${ }^{35,36}$ Interpenetrating networks are formed by blending aluminum polyphosphate with thermoplastic latexes, ${ }^{37}$ producing films with improved adhesion to many substrates. ${ }^{38}$

\section{Other Systems}

Even though many hydrous non-crystalline compounds are known, research activity is largely concentrated on phosphates, as evidenced by data recovered from the SciFinder Search database. Table 1 shows the numbers of documents listed under different combinations of keywords and it shows that an important fraction of these is represented by patents.

In the case of phosphates, the major index term is prosthetic materials and prosthetics, evidencing that their biological applications have great importance. Among the various amorphous phosphates used as biomaterials calcium phosphate is the most relevant.

Amorphous calcium phosphate similarities in composition to bone and teeth make it ideal for both dental and bone restorative materials because of its excellent castability and adequate mechanical strength. ${ }^{39}$ Amorphous calcium phosphates paste has also the advantage of being very fast setting compared to crystalline calcium phosphate cements. The setting reaction is finished much faster although the initial part of the reaction proceeds at the same speed as with known cements. ${ }^{40}$ Also an increase of the amorphous calcium phosphates content on material improves its osteoconductive properties (i.e., the propensity of the material to favor bone growth when it is in contact with bone tissue) but compromises its longevity. ${ }^{41}$

The low research activity on non-phosphate compounds should not be understood as a consequence of the absence of interesting phenomena or properties but rather as a consequence of the perception of academic researchers that do not see these compounds as fashionable and proper research topics.

A special case is that of silica. There are many different silica types, including some important industrial products with unique properties. The variety and complexity of their structures and properties have been often overlooked and many unexpected results were produced in the past few years. ${ }^{42-44} \mathrm{~A}$ recent contribution from this laboratory shows that the sorption of surfactants and $\mathrm{NaCl}$ in silica nanosized particles creates unexpected spatial distributions of solutes, that were evidenced by electron spectroscopy imaging in the transmission electron microscope (ESI/TEM). The particles absorb both $\mathrm{Na}^{+}$and $\mathrm{Cl}^{-}$ions in similar amounts, from aqueous solutions, thus confirming that Stöber silica nanoparticles are highly porous and have a potential usefulness as carriers of small molecules and ions, due to the small particle size, exceptional colloidal stability added to this newly found sorption behavior. ${ }^{45}$

\section{Formation: Thermodynamics and Mechanisms}

Important questions on aluminum phosphate particles are the mechanisms for particle formation and growth, as well as particle stability within dispersions and also during

Table 1. Number of documents (papers, conference abstracts and patents) and of patents only, recovered from the SciFinder Search database ${ }^{\circledR}$ using various combinations of keywords after removing duplicates. The search and data filing were performed on June 29,2006

\begin{tabular}{lll}
\hline Keywords or phrases & Documents & Patents \\
\hline Amorphous hydrous inorganic compounds & 54 \\
Amorphous hydrous (Non crystalline) & $49(1)$ & $35(1)$ \\
Amorphous hydrous oxides (Non-crystalline) & $434(34)$ & $92(15)$ \\
Amorphous metal hydroxide (Non-crystalline) & $190(4)$ & $123(3)$ \\
Amorphous phosphate (Non crystalline) & $723(180)$ & $130(27)$ \\
Amorphous borate (Non crystalline) & $75(1)$ & $26(1)$ \\
Amorphous silicate (Non crystalline) & $791(13)$ & $242(7)$ \\
Non-crystalline metal hydroxo-salt & 3 & 3 \\
Non-crystalline aqueous inorganic solids & 47 & 10 \\
\hline
\end{tabular}


milling and drying operations. The particles are noncrystalline and certainly well away from a state of thermodynamic stability and their functionality can only be controlled by the kinetics of the various transformations taking place during their life cycle.

In recent years, there has been progress in the making of new structured, micro and mesoporous aluminophophates in understanding this mechanism of formation. ${ }^{46}$ The formation of these structured compounds is now rather well understood, based on chemical information and well-documented aluminosilicates similarities ${ }^{47}$ However, the early stages of amorphous phosphates formation are less clear.

Concerning particle formation, this is generally considered in the literature as the outcome of a phase separation driven towards solid-liquid phase equilibrium. However, the formation of the amorphous aluminum phosphates referred to this work is rather a liquid-liquid phase separation, where the particles are made out of concentrated and highly viscous liquid phase contacting a dilute phase. Direct evidence on phosphate liquid-liquid phase separation is observed in $\mathrm{Cr}^{3+}$-polyphosphate- $\mathrm{H}_{2} \mathrm{O}$ system $^{48}$ where a dark green aqueous phase is formed contacting a clear phase. Other related evidence is the formation of thermoreversible gels, ${ }^{49,50}$ in which ionic electric conductance is essentially unaltered by gel formation, showing that there is little ion immobilization, if any.

Two basic mechanisms are usually considered for the formation of particles out of a supersaturated solution: nucleation and growth or spinoidal phase separation. However, we should recall that this fundamental question is by itself under debate and these mechanisms have been considered insufficient to account for organic nanoparticle formation since some new views were introduced by work based on Monte Carlo simulations. ${ }^{51}$ This question is now open to research but nucleation and growth do not seem to have great importance since the particles do not grow upon aging under many storage conditions, displaying only limited Ostwald ripening. ${ }^{52}$

Models for aluminophosphate formation are based on structures of one-dimensional chains (which can be considered as building blocks), two-dimensional porous layer, and three-dimensional open-framework. Basically, as mentioned previously, complex structures can be obtained from raw metastable linear chains by: (i) dynamic hydrolysis of Al-O and P-O bonds; (ii) formation of terminal $\mathrm{AlOH}$ and $\mathrm{POH}$ groups; and (iii) subsequent intra or inter chains condensation, with loss of water, Figure 3. ${ }^{11,53}$ The chain condensation causes crosslinking, yielding a structured material.

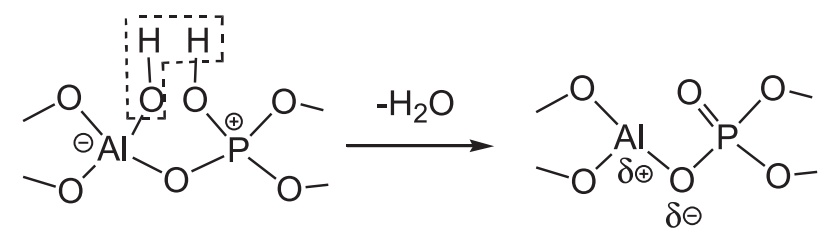

Figure 3. Dehydration process in aluminum phosphate chain through $\mathrm{Al}-\mathrm{OH}$ and $\mathrm{P}-\mathrm{OH}$ terminal bonds condensation.

During the particle growth, the condensation to build new structures can be made among different types of chain and also among chains and aluminum and/or phosphate solutes that can still coexist in the system. Such aluminum and phosphate ions are dependent of reaction $\mathrm{pH}$, and these species can be incorporated between the chains, which represent a new variable to obtain different functionalities. This is commonly called "chain encapsulation". ${ }^{11}$

The chemical concepts used to understand the formation of the structured aluminophosphates may be extrapolated to amorphous phosphates formation, since it is observed in some cases that the rapid precipitation of primary chains results in a non-crystalline structure, with poorly arranged layers. ${ }^{11}$

Pigment aluminum phosphate particle sizes are highly stable in aqueous solutions, even in the absence of surfactant or polyelectrolytes and in the presence of common salts. They are thus classified as hydrophilic particles, as opposed to e.g. crystalline iron phosphates. This is easily understood considering that the particles are swollen under water, behaving as for instance the nanosized Stober silica particles, ${ }^{43,44}$ and probably sharing some of their colloidal and sorption properties. Crystallization of the amorphous particles under water has not been observed, under usual handling conditions.

Pressing questions currently requiring further research are the refinement of particle structure, the kinetics and mechanism of particle formation and behavior in aqueous dispersion, in the presence of dehydrating or swelling agents. This is being done using the conceptual framework of polymer solutions, gels and phase equilibria rather than widespread ideas on inorganic (crystalline) particles. In the long run, a more specific conceptual framework will be needed for amorphous aqueous inorganic particles, benefiting also from ideas developed for glasses and ionic liquids.

\section{Conclusions}

The chemistry of non-crystalline phosphates is far more complicated and much more demanding that one may assume at first. In fact, the research on non-crystalline 
phosphates is a great challenge, but it can also be very rewarding. From biomaterials to new pigments, the innovative technologies referred to in this work give clear evidence that a better understanding of these materials structure-property relationships can provide new avenues for developing many new functional materials and perhaps even for creating new functions.

As more data are gathered and improvements in the analytical techniques are achieved, new paths for the research on non-crystalline solids will be open leading to an even wider range of scientific opportunities and industrial applications.

\section{Acknowledgments}

The authors acknowledge the support of CNPq/PADCT (Instituto do Milênio de Materiais Complexos) and Bünge Fertilizantes (São Paulo).

\section{Supplementary Information}

Aluminum phosphate preparation, as described in U.S. Pat. Appl. Publ. 20060045831, ${ }^{29}$ according to www.uspto.gov (on November 7, 2006).

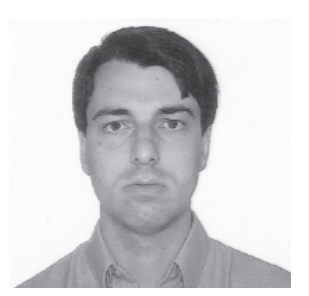

Renato Rosseto received his B.Sc degree in chemistry from the Universidade Estadual de Campinas (Unicamp) in 1995 and concluded his Ph.D. in organometallic chemistry in Prof. Maria D. Vargas group at Unicamp in 2002. From 2003 to 2005 he was a postdoctoral fellow at California State University, Northridge, working on labeledphospholipid synthesis under the supervision of Prof. Joseph Hajdu. He is now an associate researcher in Prof. Fernando Galembeck laboratory.

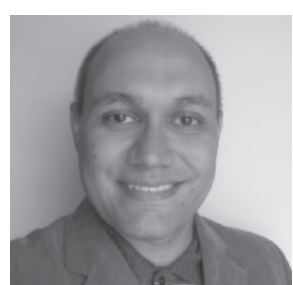

Ádamo César M. A. dos Santos graduated in chemistry at the Universidade de São Paulo (USP) in 2000. His Ph.D. in Chemical Sciences was initiated in 2001 and completed in 2005 under the supervision of Prof. Marilda D. Assis at Universidade de São Paulo. From 2004 to 2005, as part of his Ph.D., he worked with Prof. John LindsaySmith in the University of York. He is currently at the Universidade Estadual de Campinas (UNICAMP), work- ing as an associate researcher in Prof. Fernando Galembeck laboratory, where he studies the physicalchemical properties of aluminum phosphate nanoparticles.

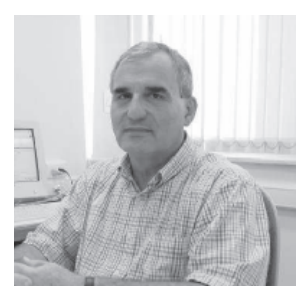

Fernando Galembeck holds Chemistry B.Sc. (1964) and Ph.D. (1970) degrees from USP and was a post-doc in the Universities of Colorado and California (Davis). He taught at USP and Unesp (Araraquara) and he has been in Unicamp since 1980 having served as the Head of the Institute of Chemistry and university General Coordinator (vice-rector). He also served in many governmental agencies (Fapesp, Capes, CNPq, MCT), learned societies ( $S B Q, S B P C, S B M M$, IACIS, ABC), journals (Química Nova, JBCS, JCIS, AABC, BCCS) and as a consultant to a number of companies, having received many prizes.

\section{References}

1. Wagner, C.N.J.; J. Non-Cryst. Solids 1978, 31, 1; Burrell, L.S.; Johnston, C.T.; Schulze, D.; Klein, J.; White, J.L.; Hem, S.L; Vaccine 2001, 19, 275; Klein, J.; Ushio, M.; Burrel, L.S.; Wenslow, B.; Hem, S.L.; J. Pharm. Sci. 2000, 89, 311; Okada, S.; Yamamoto, T.; Okazaki, Y.; Yamaki, J.; Tokunaga, M.; Nishida, T.; J. Power Sources 2005, 146, 570; Sales, B.C.; Boatner, L.A.; Ramey, J.O.; J. Non-Cryst. Solids 2000, 263264, 155.

2. Wicks, J.D.; McGreevy, R.L.; J. Non-Cryst. Solids 1995, 193, 23.

3. Dalba, G.; Fornasini, P.; Grisenti. R.; Rocca, F.; J. Non-Cryst. Solids 2004, 345, 7; Raberg, W.; Ostadrahimi, A. H.; Kayser, K.; Wandelt, K.; J. Non-Cryst. Solids 2005, 351, 1089.

4. Zallen, R.; The Physics of Amorphous Solids, Wiley: New York, 1983.

5. Kolthoff, I.M.; Treatise on Analytical Chemistry, $2^{\text {nd }}$ ed., John Wiley \& Sons Inc: New York, 1982.

6. McBride, M.B.; Environmental Chemistry of Soils, Oxford University Press: New York, 1994.

7. Moolenaar, R.J.; Evans, J.C.; McKeever, L.D.; J. Phys. Chem. 1970, 74, 3629; Akitt, J.W.; Greenwood, N.N.; Khandelwal, B.L.; Lester, G.D.; J. Chem. Soc. Dalton Trans. 1972, 604.

8. Lima, E.C.O.; Neto, J.M.M.; Fujiwara F. Y.; Galembeck, F.: J. Colloid Interface Sci. 1995, 176, 388.

9. Cheung, T.T.P.; Willcox, K.W.; McDaniel, M.P.; Johnson, M.M.; Bronnimann, C.; Frye, J.; J. Catalysis 1986, 102, 10. 
10. Galembeck, F.; Lima, E.C.O.; Beppu, M.M; Sassaki, R.M.; Marson, N.C.; Monteiro, V.A.R. Sousa, E.F. In Fine Particles Science and Technology; Pelizetti, E., ed.; Kluwer Academic Publishers: Dordrecht, 1996, p. 267.

11. Oliver, S.; Kuperman, A.; Ozin, G.A.; Angew. Chem. Int. Ed. 1998, 37, 46.

12. Otaigbe, J.U.; Beall, G.H.; Trends Polymer Sci. 1997, 5, 369.

13. Hill, R.W.; Kehl, W. L.; Lynch, T. J.; US pat. 4,289,863 1981.

14. Kehl, W. L.; U.S. pat. 4,080,311 1978.

15. Climent, M. J.; Corma, A.; Fornes, V.; Guil-Lopez, R.; Iborra, S.; Adv. Synth. Catal. 2002, 344, 1090.

16. Pecoraro, T. A.; Chan I. Y.; US pat. 6,022,513 2000.

17. Rieser, K.; Weber C.; Welsh, W. A.; US pat. 5,698,758 1997.

18. Kumar, V.S.; Padmasri, A.H.; Satyanarayana, C.V.V.; Ajit Kumar Reddy, I.; David Raju, B.; Rama Rao, K.S.; Catal. Commun 2006, 7, 745.

19. Bautista, F.M.; Campelo, J.M.; Garcia, A.; Leon, R.M.; Luna, D.; Marinas, J.M.; Romero, A.A.; Catal. Lett. 1999, 60, 145.

20. Parida, K.; Mishra, T.; J. Colloid Interface Sci. 1996, 179, 233.

21. Bautista, F.M.; Campelo, J.M.; Garcia, A.; Luna, D.; Marinas, J.M.; Quirós, R.A.; Romero, A.A.; Appl. Catal., A 2003, 243, 93.

22. Gupta, R, K.; Adv. Drug Delivery Rev. 1998, 32, 155.

23. Baylor, N.W.; Egan, W.; Richman, P.; Vaccine 2002, 20, S18.

24. Burrell, L.S.; Johnston, C.T.; Schulze, D.; Klein, J.; White, J.L.; Hem, S.L; Vaccine 2001, 19, 282.

25. Al-Shakhshir, R.H.; Regnier, F.E.; White, J.L.; Hem, S.L.; Vaccine 1995, 13, 41.

26. Sambasivan, S.; Steiner, K. A.; WO 2,005,061,218 2005.

27. Sambasivan, S.; Steiner, K. A.; US pat 6,461,415 2002.

28. Galembeck, F.; De Brito, J.; Br PI 0.403.713-8 2004.

29. Galembeck, F.; De Brito, J.; U.S. Pat. Appl. Publ. 20060045831 2006

30. Giannelis, E.P.; Adv. Mater. 1996, 8, 29.

31. Beppu M. M.; Lima, E.C.O.; Galembeck, F.; J. Colloid Interface Sci. 1996, 178, 93.

32. Mendes, L. G.; Galembeck, A.; Engelsberg, M.; Diniz, F. B.; Colloids Surf., A 2006, 281, 99.

33. Castro, E. G.; Zarbin, A. J. G.; Galembeck, A.; J. Non-Cryst. Solids 2005, 351, 3704.

34. Castro, E. G. de; Zarbin, A. J. G.; de Oliveira, H.P.; Galembeck, A.; Synth. Met. 2004, 146, 57.
35. Galembeck, A.; Silva, S. B. C.; Silva, J. A. P.; Del Nero, J.; Optical Materials 2004, 24, 637-641.

36. Del Nero, J.; Silva, J. A. P.; Silva, S. B. C.; Galembeck, A.; Synth. Met. 2003, 135.

37. de Souza, E. F.; Bezerra, C. C.; Galembeck, F.; Polymer 1997, 38,6285 .

38. de Souza, E. F.; da Silva, M.C.V.M.; Galembeck, F.; J. Adhes. Sci. Technol. 1999, 13, 357.

39. Zaffe, D.; Micron 2005, 36, 583.

40. Bohner M.; WO 2,005,084,726 2005.

41. Nagano, M.; Nakamura, T.; Kokubo, T.; Tanahashi, M.; M. Ogawa, M.; Biomaterials 1996, 17,1771.

42. Costa, C. A. R.; Leite, C. A. P.; Souza, E. F.; Galembeck, F.; Langmuir 2001, 17, 189.

43. Costa, C. A. R.; Leite C. A. P.; Galembeck, F.; J. Phys. Chem. B 2003, 107, 4747.

44. Leite, C. A. P.; Souza, E. F.; Galembeck, F.; J. Braz. Chem. Soc. 2001, 12, 519.

45. Costa, C. A. R.; Leite, C. A. P.; Galembeck, F.; Langmuir 2006, 22,7159 .

46. Afeworki, M.; Dorset, D.L.; Kennedy, G.J.; Strohmaier, K.G.; Chem. Mater. 2006, 18, 1697; Kimura, T.; Microporous Mesoporous Mat. 2005, 77, 97.

47. Auerbach, S.M.; Ford, M.H.; Monson, P.A.; Curr. Opin. Colloid Interface Sci. 2005, 10, 220.

48. de Azevedo, M.M.M.; Bueno, M.I. M. S.; Davanzo, C. U.; Galembeck, F.; J. Colloid Interface Sci. 2002, 248, 185.

49. Lima, E.C.O.; Neto, J.M.M.; Fujiwara F. Y.; Galembeck, F.: J. Colloid Interface Sci. 1995, 176, 388.

50. Lima, E.C.O.; Galembeck, F.; J. Colloid Interface Sci. 1996, 166, 309.

51. Horn, D.; Rieger, J.; Angew. Chem. Int. Ed. 2001, 40, 4330.

52. Ratke, L.; Voorhees, P.W.; Growth and Coarsening: Ostwald Ripening in Material Processing, Springer-Verlag Telos: New York, 2002.

53. Babu, G.P.; Ganguli, P.; Metcalfe, K.; Rockliffe, J.; Smith, E.G.; J. Mater. Chem. 1994, 4, 331.

Received: June 30, 2006

Published on the web: December 6, 2006

FAPESP helped in meeting the publication costs of this article. 


\title{
Hydrous Non-Crystalline Phosphates: Structure, Function and a new White Pigment
}

\author{
Renato Rosseto, Ádamo C. M. A. dos Santos and Fernando Galembeck* \\ Instituto de Química, Universidade Estadual de Campinas, CP 6154, 13083-862, Campinas - SP, Brazil
}

Aluminum phosphate preparation as described in US Patent application (reference 29) follows. For further information, see www.uspto.gov.

In this example, $535.0 \mathrm{~kg}$ of aluminum phosphate was prepared. The wet product was dried in a "turbo-dryer" and presented characteristics of hollow particles with $15 \%$ humidity and $\mathrm{P}: \mathrm{Al}$ (phosphorus:aluminum) ratio of 1:1.50.

$940.0 \mathrm{~kg}$ of fertilizer phosphoric acid containing $55.0 \%$ of $\mathrm{P}_{2} \mathrm{O}_{5}$ was prepared. In the initial preparation phase, the acid discoloration was carried out, which lasted approximately thirty minutes, at a temperature of $85{ }^{\circ} \mathrm{C}$. For this phase, a solution with $8.70 \mathrm{~kg}$ of hydrogen peroxide containing around $50 \%$ of $\mathrm{H}_{2} \mathrm{O}_{2}$ was added to the acid. Then, the acid was diluted with $975.0 \mathrm{~kg}$ of process water, cooled to a temperature of $40{ }^{\circ} \mathrm{C}$ and then stored at the concentration of $27.0 \%$ of $\mathrm{P}_{2} \mathrm{O}_{5}$.

The aluminum source employed in this application was a commercial aluminum sulfate solution containing $28 \%$ of $\mathrm{Al}_{2} \mathrm{O}_{3}$. The solution was filtered and diluted with process water. Specifically, $884.30 \mathrm{~kg}$ of aluminum sulfate solution and $1,776.31 \mathrm{~kg}$ of process water was combined to create a solution of approximately $9.30 \% \mathrm{Al}_{2} \mathrm{O}_{3}$.

This particular experiment used as a neutralizing reagent a diluted solution of commercial sodium hydroxide containing $20.0 \%$ of $\mathrm{NaOH}$. Specifically, $974.0 \mathrm{~kg}$ of

Table 2 A standard paint formula currently used in the market and the corresponding formula using the aluminum phosphate. The amounts are given in grams

\begin{tabular}{lll}
\hline & $\begin{array}{l}\text { Standard Formula } \\
\text { using } \mathrm{TiO}_{2}\end{array}$ & $\begin{array}{l}\text { Standard Formula } \\
\text { using novel slurry }\end{array}$ \\
\hline Water & 839.79 & 361.86 \\
Propyleneglycol & 30.00 & 30.00 \\
Thickener/rheology modifier & 84.00 & 4.50 \\
Antifoaming agent & 0.60 & 1.17 \\
Sodium tetrapyrophosfate & 0.87 & 9.00 \\
Anti-oxidant & 0.87 & 0.90 \\
Dispersant & 20.94 & 11.00 \\
Ammine & 0 & 5.00 \\
AFE anionic & 7.86 & 7.86 \\
Bactericide & 4.50 & 4.50 \\
Fungicide & 4.50 & 4.50 \\
Ammonium hydroxide 25\% & 7.11 & 15.00 \\
Kaolin \# 325 & 169.50 & 169.50 \\
CaCO nat. micronized & 161.28 & 161.28 \\
Dolomite \# 325 & 300.00 & 300.00 \\
Aluminium silicate \# 1000 & 60.18 & 60.18 \\
Titanium dioxide & 534.00 & 267.00 \\
Aluminum phosphate slurry 35\% & 0 & 763.00 \\
Acrylic resin & 735.00 & 591.00 \\
Antifoaming/mineral spirit & 9.00 & 6.00 \\
Coalescing agent & 60.00 & 43.47 \\
Total/(grams) & 3030.00 & 2816.72 \\
& & \\
\hline
\end{tabular}

*e-mail: fernagal@iqm.unicamp.br 
sodium hydroxide solution with $50 \%$ of $\mathrm{NaOH}$ and $1,461.0$ $\mathrm{kg}$ of process water were mixed. The final mixture was cooled to $40{ }^{\circ} \mathrm{C}$.

The three reagents were mixed simultaneously, for approximately 30 minutes, in a reactor with 7,500 liters. During the addition of the reagents in the reactor, the mixture temperature was kept in the $40{ }^{\circ} \mathrm{C}$. to $45{ }^{\circ} \mathrm{C}$ range, the $\mathrm{pH}$ was controlled to stay in a range of 4.0 to 4.5 . At the end of the addition of reagents, the mixture was kept sloshing for approximately 15 minutes. The $\mathrm{pH}$ at this point was controlled at approximately 5.0 with the addition of a sodium hydroxide solution containing $5.0 \%$ of $\mathrm{NaOH}$. The resulting suspension was approximately $7,000 \mathrm{~kg}$ with a density of $1.15 \mathrm{~g} / \mathrm{cm}$ sup.3, presented $6.5 \%$ of solids, which represent around $455.0 \mathrm{~kg}$ of precipitate.

Then, the suspension was filtered in a press-filter resulting in $1,300 \mathrm{~kg}$ of wet cake and $5,700 \mathrm{~kg}$ of filtrate. The filtrate consisted primarily of a sodium sulfate solution $\left(\mathrm{Na}_{2} \mathrm{SO}_{4}\right)$. The cake consisted of approximately $35 \%$ solids. The cake was washed, directly in the press filter, with 3,860 liters of process water, at room temperature, being kept at a washing ratio of approximately $8.5 \mathrm{~cm}^{3}$ of the washing solution per ton of dry cake. The filtrate generated in the washing of the cake was stored for optional future use or for effluent treatment. The cake extracted from the filter, around $1,300 \mathrm{~kg}$, was then transferred to a disperser (of approximately 1,000 liters) through a peristaltic pump. The dispersed solution, containing approximately $35 \%$ of solids, had a density of $1.33 \mathrm{~g} / \mathrm{cm}^{3}$ and viscosity of $17,400 \mathrm{cPs}$.

The dispersed aluminum phosphate suspension, with approximately $35 \%$ of solids, was then pumped to a turbo- drier. The product was heated, through a hot air stream, at a temperature of $135{ }^{\circ} \mathrm{C}$. Approximately $535.0 \mathrm{~kg}$ of aluminum orthophosphate with $15 \%$ of humidity was produced. The final product was micronized and its granulometry was kept below the 400 mesh. The final analysis of the dry product presented the following results: the phosphorus content in the product was approximately $15.0 \%$; the aluminum content was approximately $8.7 \%$; the $\mathrm{pH}$ was approximately 7.0 ; the water content was approximately $15 \%$; specific density of $2.20 \mathrm{~g} / \mathrm{cm}^{3}$, and average diameter of particles from 5 to $10 \mu \mathrm{m}$.

In tests comparing a standard paint dry film to a film with aluminum phosphate, a standard market formulation of a semi-matt acrylic paint was chosen and titanium dioxide was progressively replaced by the novel aluminum phosphate product described herein. Water content and other paint components were adjusted as required. Several of the modifications in the formula in this embodiment are related to a decreased use of thickener/rheology modifier, dispersant, acrylic resin and coalescing agent.

In the formula above, a replacement of $50 \% \mathrm{TiO}_{2}$ (on a weight basis) was achieved, keeping the opacity and whiteness conditions of the dry film. In addition, the other properties of the novel product as a rheological modifier and also as a film structuring agent were explored. Comparison between the two formulas above shows that the pigments made according to embodiments of the invention will lead to additional cost reduction beyond that derived from the replacement of titanium dioxide pigment. Moreover, such gains may be obtained while producing a better performance in the applied paint film. 